\title{
REFUNDICIÓN DE DOMINIOS Y REPOBLACIÓN FORESTAL EN LA PORCIÓN ANDALUZA DE LA CUENCA DEL RÍO GUADALENTÍN
}

\author{
Eduardo Araque Jiménez \\ Área de Análisis Geográfico Regional \\ Universidad de Jaén
}

\section{RESUMEN}

La reiteración de desastres originados por el desbordamiento del río Guadalentín obligó al Gobierno, a finales del siglo XIX, a otorgar la máxima prioridad a la repoblación forestal de la porción más elevada de la cuenca, como medio más eficaz para combatir la acción devastadora de las aguas. Después de resolver el complejo problema jurídico que planteaba la titularidad de los montes (refundición de dominios), la repoblación se desarrolló a un ritmo muy lento durante el primer tercio del siglo XX debido a la carencia de medios materiales. Tras la guerra civil española, la mayor dotación presupuestaria y una legislación mucho más intervencionista propiciaron una aceleración de los trabajos de repoblación forestal y corrección hidrológica, que si bien no lograron erradicar los desastres provocados por las avenidas torrenciales, sí consiguieron, al menos, mitigar sus catastróficos efectos.

Palabras clave: Guadalentín, refundición de dominios, repoblación forestal.

\section{ABSTRACT}

The reiteration of disasters originated by the overflowing of Guadalentín River obliged the Government to give maximum priority, in the last years of XIXth century, to the reforestation of the higher area of its basin, like the most effective measure to beat the devastating action of waters. After to resolve the complex legal problem that stated the property of the plots (merger of domains), the reforestation of them was developed very slowly during the first third of XXth 
century, due to the lack of finances. When the Spanish Civil War finished, the higher consignments in the public budgets and a legislation more interventionist favoured the acceleration of the works of reforestation and the hydrologic correction, which, although they did not get to eradicate the disasters originated by torrential flood, achieved to mitigate their catastrophic effects.

Key words: Guadalentín, merger of domains, reforestation.

\section{INTRODUCCIÓN}

Como conocían perfectamente los afectados y ponían de manifiesto la mayor parte de los estudios e informes técnicos que se redactaron sobre el particular, las recurrentes avenidas e inundaciones acaecidas en la cuenca del Segura estaban asociadas, en gran medida, al deplorable estado de conservación que presentaba la cabecera del Guadalentín, su principal afluente, cuyo primer tramo discurría por tierras andaluzas ${ }^{1}$. En uno de esos trabajos, redactado a raíz de las trágicas inundaciones de 1879 y 1884, sus autores, los ingenieros de caminos Ramón García y Luis Gaztelu, no dudaban en reconocer a este río como el «autor muy principal según la opinión más generalmente admitida de la mayor parte de las catástrofes debidas a las inundaciones desde Lorca al mar, y sobre todo de las que en el año 1879, de tal manera impresionaron a toda Europa» (García y Gaztelu, reed. 2001, 4). No resulta extraño, por tanto, que el grueso de las medidas encaminadas a contener los estragos materiales y humanos que acarreaban las inundaciones se ciñera a esta cuenca. Desde luego, como ya indicaron en sus primeros trabajos los profesores Gil Olcina (1968 y 2001) y Calvo García-Tornel (1968-1969), a los autores citados no les quedaba ninguna duda de ello, por lo que insistieron reiteradamente en la urgencia y el carácter prioritario que debía darse a las actuaciones en la cuenca de este río, a fin de paliar los desastres que, de cuando en cuando, se cernían sobre la vega del Segura.

Identificada la raíz del mal, la siguiente cuestión consistía en decidir los medios más eficaces para combatirlo. A este respecto, como ha puesto de relieve Josefina Gómez Mendoza al estudiar el problema en el conjunto del territorio nacional, desde un primer momento se diferenciaron nítidamente dos grandes posturas, la de quienes apostaban por la construcción de diferentes infraestructuras en los lechos de los cauces (presas y canales de derivación), liderada por

1 Sobre la trascendencia y repercusiones de las inundaciones en la cuenca del Segura, así como en el resto del sureste peninsular, existe una abundante bibliografía que han recopilado y sistematizado Espejo Marín y Calvo García-Tornel (2003). El Instituto Universitario de Geografía de la Universidad de Alicante, por su parte, viene dedicándose desde hace ya más de dos décadas al estudio de este fenómeno. Al respecto puede verse, entre otras muchas, la obra de Gil Olcina y Morales Gil (Edic.) (1989). 
los ingenieros de caminos, y la de aquellos otros para los que resultaba fundamental la intervención en las desnudas cuencas de alimentación de los ríos (repoblación y corrección hidrológico forestal), auspiciada por los ingenieros de montes (Gómez Mendoza, 1989). Las distintas intervenciones que se efectuaron en el congreso sobre inundaciones celebrado en Murcia en 1885 resultaron sumamente ilustrativas sobre el particular ${ }^{2}$. También lo eran las consideraciones que hacía años después Eustaquio de los Reyes, a propósito, precisamente, de la avenida experimentada por el Guadalentín a comienzos del siglo XX. Venía a decir este ingeniero de montes que, en realidad, aquélla era una falsa polémica, pues como demostraban elocuentemente los acontecimientos que le ocupaban, ambos procedimientos «obran de consuno y que es inútil recurrir a uno sin la acción combinada del otro» (Reyes, 1900, 624).

A pesar de esta constatación, de todo punto lógica, en la cuenca del Guadalentín durante muchos años se trabajó en la primera de las dos direcciones apuntadas, tal y como lo prueba la construcción de los hiperembalses de Puentes y Valdeinfierno, si bien conviene advertir que su objetivo, al margen de la contención de las riadas, era incrementar la dotación de agua al extenso regadío lorquino (Gil Olcina, 2004). En las últimas décadas del siglo XIX, en vista de que los resultados obtenidos con estas grandes infraestructuras hidráulicas no eran del todo satisfactorios, se consideró abiertamente la posibilidad de empezar a trabajar en la dirección correctora y reforestadota de la cuenca, pues ya entonces se tenían sobradas evidencias de que el fenómeno de las inundaciones estaba intimamente relacionado con el estado de desnudez arbórea que presentaba la parte alta de la cuenca. De este modo, tras la creación del servicio hidrológico forestal a comienzos de $1888^{3}$, se dio la máxima prioridad, entre otras, a la intervención en la cuenca del Guadalentín. Así lo establecía una real orden promulgada a mediados de ese mismo año ${ }^{4}$, si bien el texto de la norma resultaba tan confuso, que todo hacía presagiar que, al menos en un primer momento, dejaría

2 Especialmente interesantes son las discusiones mantenidas entre Capdevila y Pardo. Para el primero, ingeniero de caminos, la derivación de las aguas del Segura y la construcción de represas y pantanos en éste y sus afluentes constituían «los medios más directos y eficaces de evitar o atenuar en gran parte las inundaciones, al mismo tiempo que ofrecen resultados más positivos, provechosos y fecundos para los pueblos inundados (citado en Serrano de la Pedrosa, 1886, 76-77). Para Pardo, las inundaciones a las que se refería Capdevila habían tenido lugar, precisamente, «en época en que ya había desaparecido casi todo el arbolado que poblaba los montes de una parte importante de la provincia de Murcia, precisamente casi todos los del término de Lorca, que es el que forma en esta provincia la cuenca del Guadalentín» (citado en Serrano de la Pedrosa, 1886, 132).

3 Real decreto de 3 de febrero de 1888. Gaceta de Madrid. 7 de febrero de 1888.

${ }^{4}$ Real orden de 28 de julio de 1888. Gaceta de Madrid. 10 de agosto de 1888. 
de atenderse a uno de los preceptos contenidos en esa normativa: aquél que concedía todo el interés estratégico a la intervención en el primer tercio de la cuenca. En efecto, si el artículo $4^{\circ}$ de la real orden citada identificaba con toda claridad la cuenca del Guadalentín como objeto prioritario de intervención, en el artículo $17^{\circ}$ se establecía que su denominación sería la de cuenca del Segura. Este hecho fue duramente criticado desde las páginas de La Reforma Forestal, que no consideraba baladí, en modo alguno, dicho cambio de denominación pues entendía que respondía al interés de los ingenieros de la comisión por justificar su residencia en la ciudad de Murcia y no en Lorca o Vélez Rubio, como hubiera sido más lógico, dada la cercanía a los montes objeto de estudio (Anónimo, 1893).

Al margen de esta interpretación, es muy posible que tal cambio respondiera, entre otras cosas, a la complejidad que presentaba cualquier actuación territorial en la cabecera del Guadalentín, donde el uso y aprovechamiento de los montes venía siendo compartido desde antiguo entre su legítimo propietario, el duque de Medina Sidonia, y el vecindario de los tres municipios donde éstos radicaban: Vélez Rubio, María y Vélez Blanco. De hecho, hubo que posponer toda intervención en esta porción andaluza de la cuenca hasta comienzos del siglo XX, momento en el cual se puso fin al complicado proceso de refundición de dominios de los montes. Entre tanto, todo el esfuerzo de la División hidrológica forestal del Segura se concentró en Sierra Espuña, referente nacional desde finales del siglo XIX de los favorables efectos que ejercía la repoblación forestal a la hora de contener los desastrosos estragos de las inundaciones (Codorniú, 1897).

Este panorama cambió bruscamente al finalizar la guerra civil española, momento a partir del cual, como sucedió en el resto del país (Gómez Mendoza y Mata Olmo, 1992 y 2002), se redoblaron los esfuerzos materiales y humanos tendentes a conseguir la tan ansiada corrección hidrológica de la porción más elevada de la cuenca del Guadalentín (MAPA 1). A la adquisición de aquellos montes que se ofrecieron voluntariamente por sus propietarios al Patrimonio Forestal del Estado (P.F.E.) siguió el establecimiento de numerosos consorcios con los tres ayuntamientos, cuya finalidad primordial era disponer del suelo necesario para llevar a cabo la repoblación forestal de los predios municipales. Todo ello vino acompañado de la declaración de utilidad pública de los trabajos de reforestación en las distintas subcuencas de cabecera del Guadalentín, lo que confirió a la intervención repobladora la máxima prioridad y la subordinación a la misma de los intereses privados que pudieran existir sobre los montes, cuya posibilidad de expropiación quedó expedita en caso de que así lo reclamaran las circunstancias. 
Mapa 1. Río Guadalentín. Red Hidrográfica de Cabecera

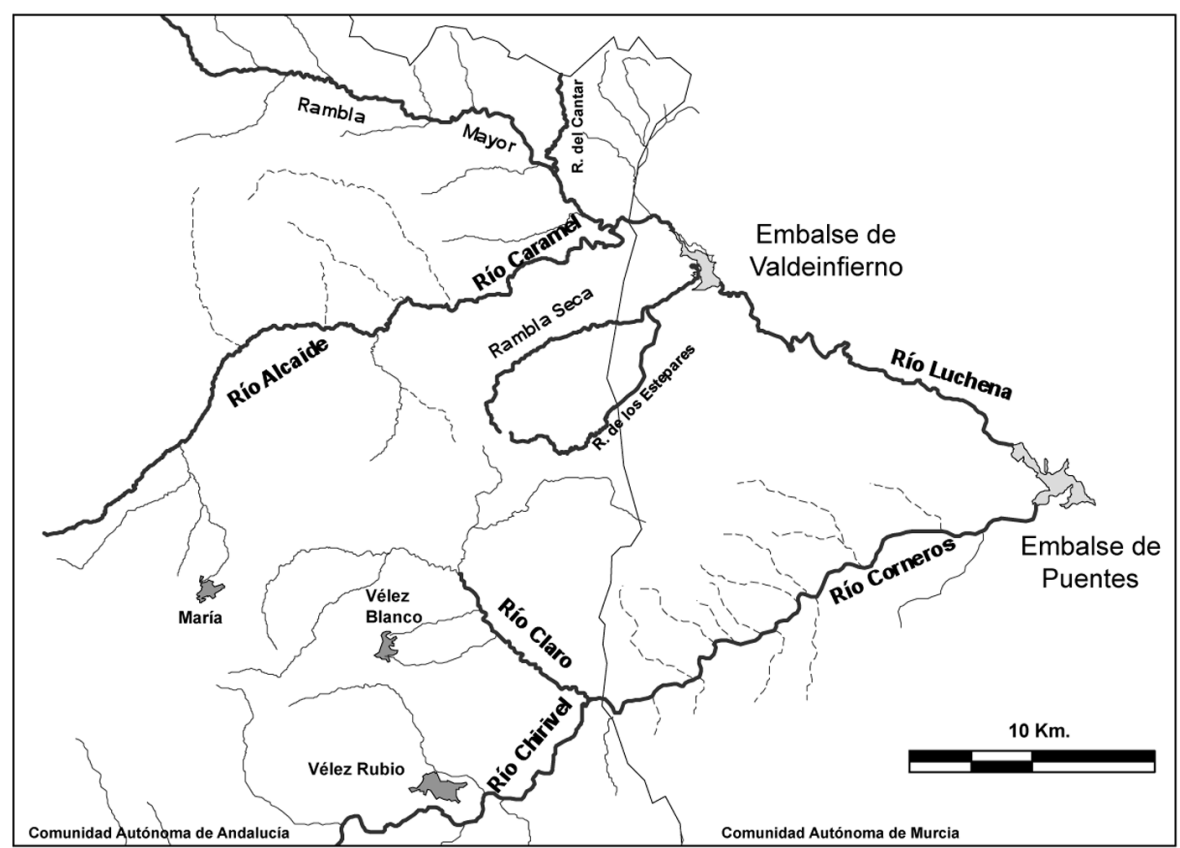

Fuente: Instituto de Cartografía de Andalucía. Elaboración propia

\section{DIFICULTADES PARA LA INTERVENCIÓN EN LA CABECERA DEL GUADALENTÍN. LA REFUNDICIÓN DE DOMINIOS}

Desde la constitución del señorío de los Vélez, a comienzos del siglo XVI (Franco Silva, 1995; Barrios Aguilera, 2007; Carretero Zamora, 2007; Roth, 2008), el dominio útil de los montes pertenecientes a la casa marquesal de Medina Sidonia vinieron ejerciéndolo los vecinos de las distintas villas integradas en el mismo, quienes estaban autorizados a la roturación de determinadas porciones de estos predios a cambio de la satisfacción de un canon anual a la casa, así como al aprovechamiento gratuito de distintos esquilmos a los que más tarde nos referiremos (Andújar Castillo, 1996). Debido a este ejercicio del dominio útil por parte del vecindario, en 1879 la totalidad de estos montes se incluyeron entre los públicos de la provincia de Almería, sometiéndose sus aprovechamientos desde entonces a los mismos planes anuales por los que se regían el resto de los predios de esta naturaleza. Pero los vecinos, acostumbrados secularmente a utilizar los esquilmos de forma gratuita o semigratuita, rechazaron de plano tal imposición (Lentisco Puche, 1996), por lo que José María Escribano, a la sazón ingeniero 
jefe del distrito forestal de Almería, propuso al gobernador civil de la provincia en 1882, que se extinguieran totalmente las servidumbres, incompatibles con la conservación y fomento del arbolado, y que se procediera en un breve plazo a la separación de dominios entre la casa marquesal de Medina Sidonia y el vecindario (refundición de dominios). Estas propuestas formaban parte de las conclusiones de una memoria redactada por Escribano, cuya primera trascripción y publicación parcial se la debemos a Azcona Elayo (2004).

En dicha memoria se describían las principales masas forestales enclavadas en los montes de María y Vélez Blanco, reseñando las especies vegetales que los poblaban y los cursos de agua que nacían y discurrían por ellos. Por otra parte, se recogían los aspectos fundamentales de las escrituras de concordia suscritas entre la casa y los representantes de los dos municipios citados. En el caso de Vélez Blanco, las primeras escrituras se firmaron en 1858, reconociéndose a través de ellas el derecho de los vecinos al aprovechamiento gratuito del monte bajo, atocha, pastos, leñas secas y rodantes, ramoneo del monte alto y al aprovechamiento de los pinos derribados que no fueran maderables. También se reconocía la propiedad de la tierra a los roturadores que dispusieran de título legal para ello, reservándose la casa marquesal su derecho respecto a los detentadores o roturadores arbitrarios. Años más tarde, en 1870 , volvieron a reunirse las dos partes para reafirmarse en los derechos asignados al vecindario en 1858, aunque ahora se hacían extensivos también de forma expresa a los habitantes de Vélez Rubio. Pero el motivo fundamental de este nuevo acuerdo no era otro que poner coto a la crítica situación en que se encontraban los montes poblados de esparto como consecuencia del mal uso que se había venido haciendo de esta planta por parte de los recolectores, contrario a cualquier sistema racional de explotación. A este respecto conviene recordar, siguiendo a Andrés Sánchez Picón, que a partir de 1862 tuvo lugar en toda la provincia de Almería una «explosión recolectora de esparto» (Sánchez Picón, 1992, 262), propiciado por el alza espectacular que experimentaron los precios, fruto del constante incremento de la demanda exterior de este producto, especialmente de la procedente de las Islas Británicas. La sobreexplotación de los montes a la que condujo esta excelente coyuntura del mercado provocó una acelerada decadencia de los espartizales, que no sólo incidió negativamente sobre los ingresos anuales que percibía la casa marquesal, sino que también privó a una buena parte de los vecinos de un recurso imprescindible para su subsistencia. Por tal motivo resultaba más urgente, si cabe, buscar soluciones consensuadas capaces de superar tan lamentable estado.

Los acuerdos alcanzados en esta nueva escritura de concordia limitaban a noventa días el período en el que podía recolectarse el esparto; correspondiendo al Ayuntamiento de Vélez Blanco fijar los días de inicio y fin de la cosecha. Cada recolector debía abonar un pequeño canon de 0,75 pesetas por carga de esparto 
extraída (dos quintales), pagaderas en cualquiera de las tres aduanas abiertas por el municipio para este fin. La cantidad total recaudada se repartiría a partes iguales entre el municipio y la casa marquesal. Para ejercer un mayor control sobre esta clase de aprovechamiento se aumentaba la plantilla de guardería hasta 12 efectivos, asumiendo la casa el sueldo de la mitad de ellos, al margen de los cuatro guardas que ya trabajaban a su servicio. Por último, aunque nada tenía que ver con el esparto, también se incluía en este acuerdo el derecho de los vecinos a aprovechar los pinos derribados por accidentes naturales cuya caña tuviera menos de diez cuartos de largo, así como los tocones de los pinos cortados por la casa marquesal.

En cuanto a la escritura de concordia con el Ayuntamiento de María, firmada en 1876, la casa de Medina Sidonia reconocía a los vecinos prácticamente los mismos derechos que ya venían ejerciendo los habitantes de Vélez Rubio y Vélez Blanco, incluido el nuevo sistema de aprovechamiento del esparto. De este acuerdo quedaba excluida la dehesa de La Alfahuara, que continuaría siendo de uso exclusivo de la casa marquesal. Se trataba, sin duda, del bien más preciado de la familia, tanto por su extensión (3.500 fanegas), como por su exuberante riqueza arbórea, cifrada a mediados del siglo XVIII en 80.000 pinos y 280.000 encinas, utilizada por su dueños y amistades para la práctica de la actividad cinegética y otro tipo de actividades recreativas (Felices de la Fuente y Giménez Carrillo, 2007).

Las consecuencias de esta forma compartida de aprovechamientos habían sido nefastas para los montes, cuyo deterioro ecológico y paisajístico resultaba cada día más preocupante. Ni siquiera su inclusión entre los montes públicos de la provincia y la obligatoriedad de someter anualmente sus aprovechamientos a un plan de explotación razonado, científico y ordenado, había sido capaz de poner freno a semejante estado de decadencia. José María Escribano entendía que gran parte de la responsabilidad correspondía a los vecinos, que nunca habían atendido a las formalidades ni a los requerimientos expresados en los planes de aprovechamientos, por entender que la forma de utilización de los montes era de su única y exclusiva competencia. Así, tanto el aprovechamiento de los pastos como el de las leñas, se efectuaban de forma tan abusiva, que estaban ocasionando un notable perjuicio a la cubierta arbórea, cuya desaparición se producía a un ritmo vertiginoso. Tampoco el esparto, a pesar de los acuerdos firmados, se hallaba en mejor situación, pues los vecinos seguían extrayéndolo en cualquier época del año y al margen de la edad y del estado vegetativo de la planta.

Todas estas razones, como ya avanzábamos, llevaban a Escribano a pedir la refundición de dominios, de tal forma que una parte de los montes quedara en propiedad exclusiva de la casa de Medina Sidonia y la otra en poder de los pueblos, diferenciándose, claro está, las partes que correspondían a cada uno de los tres municipios. Para ello, tanto la casa marquesal como los tres ayuntamientos implicados, debían 
contratar a sus respectivos peritos para que tasaran el valor del suelo y el vuelo de cada uno de los montes y propusieran su asignación a las distintas partes.

Sólo la casa marquesal cumplió con esta petición, contratando a un perito agrónomo que, acto seguido, emitió un informe en el que llegaba a la conclusión de que las servidumbres de la propiedad resultaban incompatibles con la existencia de los montes, por lo que recomendaba su inmediata refundición. Ante la ausencia de los restantes informes, la comisión provincial consideró que debía procederse en el sentido manifestado por el perito agrónomo. Así lo propuso a la Dirección General de Agricultura, Industria y Comercio, que sin dilación lo pasó a información de la Junta Facultativa de Montes. Ésta se pronunció en 1883, acordando, en primer lugar, que procedía instruir el oportuno expediente para incluir en el catálogo de montes públicos exceptuados de la desamortización, tanto los montes pertenecientes al duque de Medina Sidonia, como los de propiedad de los Ayuntamientos de María y Vélez Blanco y los que poseían mancomunados este último municipio y Vélez Rubio. En ese documento deberían quedar fijados los respectivos derechos de cada uno, de acuerdo con la letra de las escrituras públicas legitimadas por la autoridad competente. En caso de no estar legitimadas esas escrituras, convenía realizar cuanto antes nuevas concordias y proceder a su sanción por la autoridad competente. Una vez aclarados estos extremos, debería proponerse lo que se considerara más conveniente, ya fuera la redención de servidumbres y cargas, ya la refundición de dominios.

Tras el pronunciamiento del Consejo de Estado durante ese mismo año, apoyando la tesis de la Junta Facultativa de montes, el asunto quedó aparcado, entre otras razones, porque hubo que esperar a que se aprobaran oficialmente las escrituras de concordia. Cuando se reabrió el expediente, se había hecho cargo del distrito forestal otro ingeniero de montes, José Ramón Inchaurrandieta, que en su primera valoración de la situación llegó a la conclusión de que el expediente abierto por su antecesor sobre refundición de dominios no era reglamentario, ya que estaban mal fundamentadas las bases establecidas por Escribano. La refundición, tal y como preceptuaba la ley de montes de 1863, sólo procedía si el suelo del monte o los montes en cuestión eran de carácter público y el vuelo pertenecía a un particular. Al margen de ello, apreciaba que la división de dominios perjudicaría los intereses de los pueblos y favorecería el de los particulares, por lo que proponía la anulación del expediente abierto. Eso sí, para hacer compatibles las servidumbres con la conservación de los montes era necesario regular de modo preciso los aprovechamientos, lo cual implicaba la dotación de una nueva plaza de ingeniero en el distrito, consagrado, entre otras, a esta tarea.

De nuevo, la Junta Facultativa volvió a pronunciarse, exigiendo en este caso la redacción urgente de un estudio en el que se estableciera de forma minuciosa la naturaleza, cantidad y modo de ejecución de los disfrutes que realizaban los vecinos de los tres municipios y la casa marquesal, determinando con precisión a partir 
de esos datos sus efectos sobre el suelo arbóreo y la compatibilidad de tales aprovechamientos con la conservación y repoblación del arbolado. El estudio requerido fue presentado por Inchaurrandieta a finales de mayo de 1891, después de permanecer en comisión de servicio en la zona desde el mes de marzo. En el mismo se aseguraba que la casa marquesal eludía toda intervención de la Administración en sus dominios, y que los pueblos no conocían freno en sus disfrutes, todo lo cual había dado lugar a que el arbolado se encontrara completamente destrozado. Por su parte, los aprovechamientos de pastos y leñas del monte bajo se hallaban sin regularizar, lo cual resultaba pernicioso para su conservación. A pesar de todo, consideraba que ambos dominios eran compatibles si se sujetaban a los planes elaborados por el servicio facultativo, para lo cual resultaba indispensable dotar de mayor personal técnico y de agentes de guardería a los montes de toda esta zona; una solución que fue muy bien acogida por los habitantes, tal y como recogía de manera muy expresiva la prensa local, que adivinaba funestas consecuencias en caso de que se optara por la refundición: «Si los montes se dividiesen y pasaran los unos a propiedad particular y los otros al dominio absoluto de los pueblos, ¡buena la hubiéramos hecho! En el transcurso de pocos años, nuestros montes quedarían como los de la Luna, y como algunos de la Tierra que no tienen por qué envidiarlos, y que manifestando un atraso patente de los pueblos, que así los conservan por su ignorancia, no saben que son los cementerios de la agricultura ${ }^{5}$.

La respuesta de la Junta Facultativa tardó más de un año en producirse. En el dictamen, emitido en julio de 1892, calificaba de ilusoria la compatibilidad que sostenía Inchaurrandieta. La práctica había demostrado que los intereses de casa marquesal eran opuestos a la conservación del arbolado, pues según las concordias, ésta podía cortar libremente los pies que le apetecieran sin restricciones de ninguna clase. Por tanto, el máximo órgano de la administración forestal entendía que debía instruirse un expediente para la división de los montes en dos grupos, a fin de que sobre cada uno de ellos se consolidara el dominio pleno y exclusivo de cada comunero en su disfrute. Entre tanto se resolvía esta cuestión, debía destinarse un ingeniero de montes y tres capataces a la zona, para que velaran por el cumplimiento de la legislación forestal en lo que atañía a los aprovechamientos de los montes públicos. El Consejo de Estado apoyó esta propuesta y mandó que se instruyera con urgencia el expediente para la división, asignándose esta tarea a un ingeniero con residencia en Vélez Rubio. Semejante responsabilidad recayó en Domingo Olazábal, ingeniero de montes al que se confió comisión oficial para este

5 Esta frase aparecía dentro de un artículo titulado «Cuestión importantísima», publicado en el periódico El Triunfo, de Velez Rubio, y reproducido por la Revista de Montes. No 344. 1891. Págs. 211-213. 
exclusivo menester, asistido por el arquitecto Plácido Virgili. La casa de Medina Sidonia, por su parte, nombró como representante a otro ingeniero de montes, Victoriano Deleito, mientras que el Ayuntamiento de Vélez Blanco eligió a un perito. Ni el Ayuntamiento de Vélez Rubio ni el de María eligieron a representante alguno, por lo que, en la práctica, Olazábal tuvo que actuar en su nombre.

A mediados de 1898, Olazábal remitió a la Dirección General de Agricultura, Industria y Comercio la memoria ${ }^{6}$ y demás documentos elaborados (planos, copias y actas) durante su estancia en la zona, todos los cuales se aprobaron por el Ministerio de Fomento un año después. En dicha memoria, que ha sido objeto de un estudio específico (Alcocer Martínez y otros, 1998), y se ha publicado parcialmente (Lentisco Puche, 1993), se reconocían a la casa marquesal, en el término de Vélez Blanco, 49 montes con una cabida conjunta de 10.122,5 hectáreas, apreciadas en 386.373 pesetas. Todos estos montes formaban tres grandes grupos: los dos primeros situados en la porción septentrional del término limítrofe con La Puebla de Don Fadrique y Caravaca de la Cruz, Los Barrancos y Rambla Mayor (Tapia, 1964); y el tercero, Sierra Larga y Estepares, en la parte occidental que lindaba con Lorca. A los municipios de Vélez Blanco y Vélez Rubio de forma mancomunada se les asignaron 60 montes con una extensión de 14.852,3 hectáreas, valoradas en 392.561 pesetas, y distribuidas por la porción meridional del término de Vélez Blanco. La totalidad de estos montes, excepto una pequeña superficie que Olazábal calculaba que tendría de cabida 500 hectáreas, vertían aguas a la cuenca del Guadalentín.

Al Ayuntamiento de María, en su propio término, se le asignaban 15 montes con una cabida conjunta de 4.094 hectáreas, valoradas en 163.858 pesetas, mientras que a la casa marquesal correspondían 5 montes (excluida la dehesa de la Alfahuara) con una extensión total de 1.601 hectáreas, apreciadas en 61.636 pesetas. De estos últimos, 4 montes vertían aguas al Guadalquivir. En cambio, de los 15 montes de María, 9 pertenecían claramente a la cuenca del Guadalentín.

La distribución espacial de cada una de estas grandes partes, en consonancia con la asignación que se hizo definitiva en 1912, después de que la casa marquesal exigiera una aclaración sobre la división efectuada ${ }^{7}$, puede verse en el MAPA 2. Hemos tomado como base para su elaboración el mapa actual de montes públicos, por lo cual, obviamente, existen numerosas imprecisiones derivadas de la evolución territorial que han sufrido estos predios durante el último siglo. A pesar de ello, creemos que puede ilustrarnos perfectamente sobre el resultado final del proceso de refundición.

6 Olazábal, D. (1898): Memoria sobre refundición de dominios en los montes de María y Vélez Blanco. Provincia de Almería. Original.

7 Real decreto de 11 de julio de 1912. Gaceta de Madrid. 12 de julio de 1912. 
Mapa 2. Asignación de montes tras la refundición de dominios

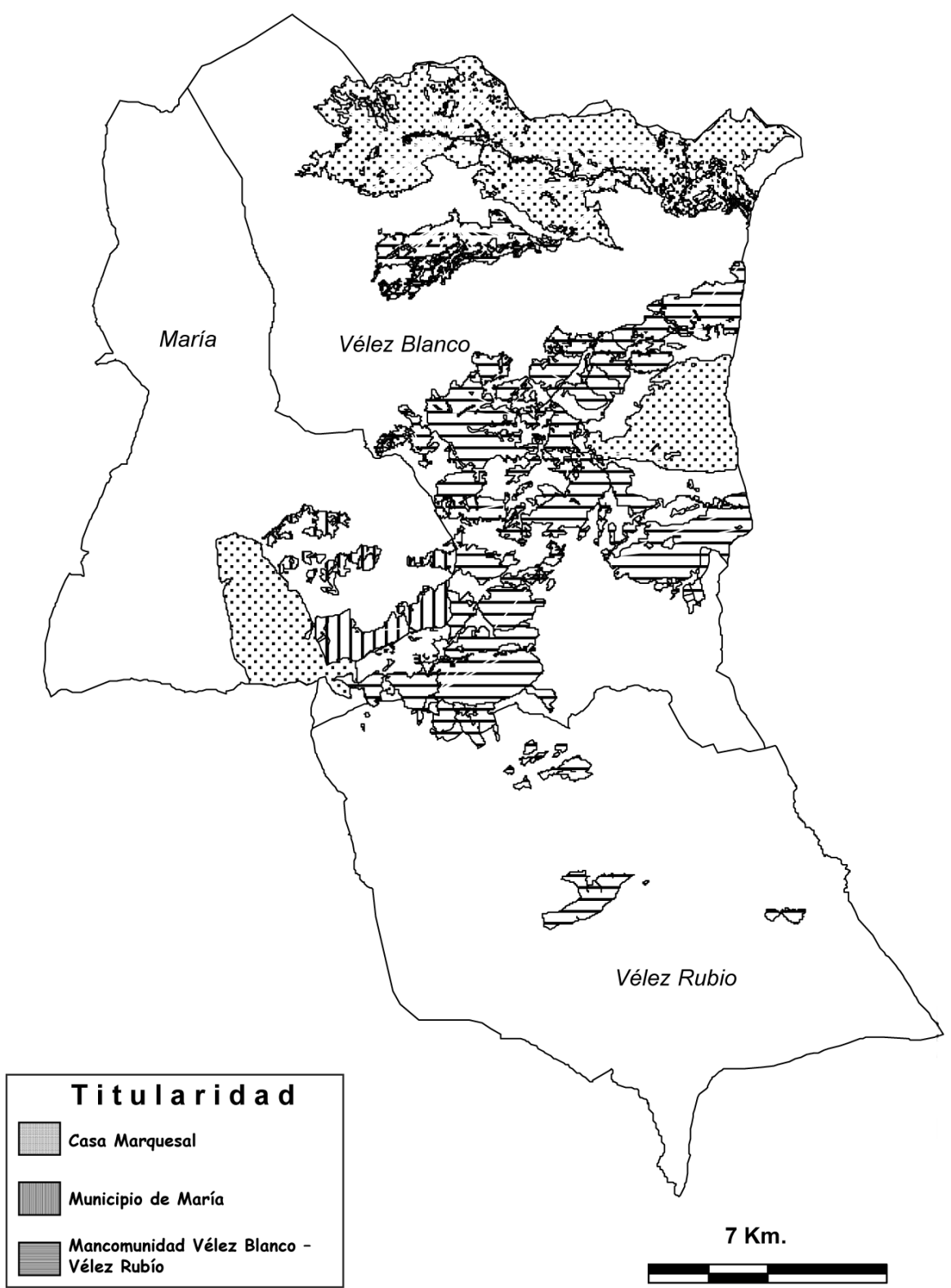

Fuente: Consejería de Medio Ambiente. Elaboración propia. 
Además de cumplir con el objetivo de establecer una distribución equilibrada y equitativa de los montes entre las partes implicadas, el trabajo elaborado por Domingo Olazábal contenía sustanciosas apreciaciones sobre el medio físico y biológico de la zona, buena parte de las cuales procedían, no cabe duda, de las contenidas en la «Memoria de reconocimiento de la cuenca del Guadalentín»" elaborada por los tres ingenieros de montes que integraban la comisión de repoblación de la cuenca del Segura, José Musso, Ricardo Codorniz y Juan Ángel de Madariaga (Martínez Artero, 2001), y de la «Reseña física y geológica de la región norte de la provincia de Almería», formada por Manuel Cortázar (1875). Especialmente interesantes resultaban sus consideraciones sobre los procesos de denudación y su íntima relación con la pérdida de tapiz vegetal, por lo que reclamaba la puesta en marcha con la máxima urgencia de un plan de repoblación forestal que viniera a frenar los desastrosos efectos de la acción erosiva. En aquellos enclaves de suelos más deleznables, afectados por corrimientos y profundos deslizamientos, Olazábal estimaba que esa acción reforestadora no bastaba por sí sola, por lo que debía completarse con el establecimiento de grandes diques transversales que ayudaran a corregir las profundas vaguadas y dieran consistencia a las vertientes de las mismas. Respecto a la adquisición por parte del Estado de los montes adjudicados a la casa marquesal, asunto sobre el cual también se le había pedido opinión, Domingo Olazábal consideraba que debían comprarse todos los montes que le habían correspondido en Vélez Blanco, tanto los de la porción septentrional del término, que comprendía casi toda la cuenca de la Rambla Mayor y algunos barrancos que vertían al río Luchena, como los situados en Sierra Larga y Estepares, que afectaban a Rambla Seca y a otros riachuelos que ya en el término de Lorca venían a desembocar en las aguas del pantano de Valdeinfierno. En el término municipal de María proponía la adquisición de un solo monte, Solana de la Sierra y Hoya de las Yeguas, enclavado en la parte más elevada de la Sierra de María, cuyas aguas vertían a la Rambla de Chirivel y, en menor medida, al río Alcalde.

El importe total de las más de 10.000 hectáreas propuestas para su adquisición por el Estado, según la valoración realizada por Olazábal en su documentada memoria, ascendía a casi 400.000 pesetas, a las cuales había que añadir otras 50.000 pesetas en las que valoraba las 500 hectáreas de roturaciones agrícolas próximas a los múltiples cortijos dispersos por la sierra, cuyo control resultaba, si cabe, más apremiante que el de los propios montes, por tener origen en ellas la mayor parte de los arrastres que se depositaban en el vaso del pantano de Valdeinfierno. Aunque las cifras que se barajaban no resultaban muy abultadas, Olazá-

8 Véase Revista de Montes. No 296. 1889. Págs. 259-261. 
bal comprendía perfectamente que el problema que se presentaba en el conjunto de la cuenca del Guadalentín requería un esfuerzo inversor desorbitado y, en consecuencia, asumía que se estableciera un cierto nivel de prioridades a la hora de seleccionar las distintas partes de la cuenca susceptibles de intervención forestal. Pero lo que nunca pensó, estamos convencidos, es en que sus propuestas, como enseguida veremos, tardaran casi medio siglo en llevarse a la práctica.

En todo caso, el real decreto que sancionaba los acuerdos tomados por el Consejo de Estado sobre la definitiva refundición de dominios ${ }^{9}$, no sólo se mostraba conforme con las particiones efectuadas por Olazábal, sino que recogía todas sus consideraciones e instaba a una revisión en profundidad de las roturaciones efectuadas en los montes, con el fin de ejercitar los correspondientes derechos contra los roturadores arbitrarios. Por otra parte, establecía que los montes asignados a los tres municipios se conceptuaran como públicos, se exceptuaran de la desamortización y se sometieran a los planes de aprovechamientos, inspección y vigilancia del distrito forestal de Almería. Y, por último, mandaba que se procediera de forma inmediata a la repoblación de los montes de los tres pueblos.

\section{DESARROLLO INICIAL DE LOS TRABAJOS DE REPOBLACIÓN Y CORRECCIÓN HIDROLÓGICO FORESTAL}

La penuria de las arcas públicas impidió al Estado, tal y como había aconsejado Olazábal, adquirir los montes que se habían adjudicado a la casa marquesal. En su lugar, distintos propietarios de la comarca y otros forasteros fueron haciéndose paulatinamente con el control de esta suculenta masa de montes que la casa de Medina Sidonia puso en venta a partir del mismo instante en que se aprobó la refundición. De todos esos propietarios, el que llegó a acaparar una mayor cantidad de tierras fue Pascual Arias Vázquez, un gran hacendado natural del vecino municipio granadino de La Puebla de Don Fadrique que, como mínimo, llegó a poseer 25 de los 49 montes asignados a la casa tras la refundición (Motos Miras, 1960).

Así las cosas, a finales de 1901, sendos reales decretos de la misma fecha ${ }^{10}$, venían a declarar de utilidad pública, a los efectos de la expropiación forzosa, los trabajos hidrológico-forestales proyectados en las vertientes septentrional y meridional del río Alcaide, pertenecientes a la primera y segunda porción, respectivamente, de la cuenca del río Luchena, afluente de cabecera del Guadalentín. Se trataba, a juicio de los ingenieros ya mencionados, y de otros que habían

9 Real decreto de 21 de septiembre de 1900. Gaceta de Madrid. 27 de septiembre de 1900.

10 Real decreto de 15 de octubre de 1901. Gaceta de Madrid. 16 de octubre de 1901. 
reconocido la cuenca durante los últimos años del siglo XIX (Martínez Artero, 2001), del ámbito territorial que requería una intervención más urgente, pues los voluminosos arrastres que tenían lugar en sus desnudas vertientes después de cada uno de los frecuentes aguaceros que azotaban la zona eran los responsables de la inutilización de una infraestructura tan costosa como el pantano de Valdeinfierno, donde desembocaban las aguas del Alcaide. Por otro lado, la actuación estaba encaminada a contener los movimientos de las laderas, que amenazaban seriamente al núcleo urbano de María, cuyo caserío se había visto afectado en numerosas ocasiones por las avalanchas de piedras y lodo procedentes de la cara norte de la Sierra de María (Mira, 1917).

Los trabajos de corrección dieron comienzo en 1902, centrándose en un primer momento en la Sierra de María, donde el Estado había adquirido al pueblo de ese nombre el monte Umbría de la Virgen, y a dos particulares sendos enclavados que se hallaban dentro del mismo. En conjunto, la superficie que pasó a manos estatales ascendió a 434,2 hectáreas, tal y como precisaba la rectificación del catálogo de montes de utilidad pública de la provincia de Almería que se realizó en $1909^{11}$. Hasta finales de 1906 se habían logrado corregir los principales barrancos de ese monte con la construcción de 126 diques de piedra en seco, además de haberse plantado y sembrado 100 hectáreas, de las que sólo podían considerarse realmente repobladas 40, pues las duras condiciones climáticas habían ocasionado numerosas marras (Anónimo, 1907). No era lo peor la lentitud del ritmo repoblador; mucho más grave resultaba comprobar, como se aprestaba a denunciar Ricardo Codorniú con motivo de las copiosas lluvias de septiembre de 1906 en toda la cuenca del Segura, que mientras el Estado invertía cuantiosas sumas en los trabajos forestales de conservación, las talas y roturaciones avanzaban a una velocidad de vértigo en la cuenca de la Rambla Mayor, sin que la lentitud de la administración forestal fuera capaz de poner freno a semejante desmán (Codorniú, 1906).

Con posterioridad a 1907, los trabajos se reactivaron y se extendieron por el resto de las vertientes seleccionadas, de manera que una década después se habían logrado repoblar 2.000 hectáreas mediante siembras y plantaciones de pinus nigra, pinus pinaster y pinus halepensis. Además, como actuaciones complementarias a la obra correctora y repobladora, se construyeron tres casas forestales, una para personal técnico y dos para guardería; un vivero en el cerro del Gabar y 18 kilómetros de pistas forestales para facilitar el acceso a los montes a los obreros que participaban en la tareas repobladoras (Mira, 1917).

Estas actuaciones, en todo caso, resultaban completamente insuficientes para la gravedad del problema planteado, tal y como venía a demostrar la memoria

11 Real orden de 17 de marzo de 1909. Gaceta de Madrid. 5 de mayo de 1909. 
elevada a la Confederación Sindical Hidrográfica del Segura por José Musso, ingeniero de montes de la misma, en $1928^{12}$. En dicho informe, Musso reconocía el interés histórico mostrado por el Estado de cara a la protección de los montes situados aguas arriba del pantano de Valdeinfierno, aunque señalaba que los medios habían sido tan escasos que «en cerca de treinta años se han podido repoblar, y no completamente, sólo las partes altas de las vertientes al vaso, pero nada se ha podido hacer en las numerosas roturaciones existentes en esas vertientes, cuyas tierras de labor son arrastradas al pantano por las aguas de lluvia». En consecuencia, proponía que se elaborara un plan meticuloso de repoblación y corrección torrencial de toda esta cuenca, prestando una atención muy especial a las vertientes de la Rambla Mayor y Rambla Seca, por ser las que mayores arrastres generaban. Así mismo, en dicho plan debía darse la máxima prioridad a la corrección de las vertientes de la Rambla de Chirivel, afluente del río Vélez, cuya cubierta vegetal se hallaba aún en bastante peor estado de conservación que las anteriores.

\section{EL TRASCENDENTAL IMPULSO REPOBLADOR DE POSGUERRA}

La profunda crisis en la que quedó sumido el Estado durante los años posteriores a la formulación de las propuestas de Musso hicieron inviable la adopción de cualquiera de sus propuestas. Hubo que esperar hasta el final de la Guerra Civil española para que éstas se retomaran con nuevos bríos. En ese nuevo contexto histórico, a los trabajos de repoblación y corrección hidrológico forestal de la cabecera del Guadalentín se les asignó la máxima prioridad, entre oras razones porque durante las cuatro primeras décadas del siglo XX, a pesar de los esfuerzos realizados, no se habían logrado contener los enormes estragos causados por la crecida de las aguas del río que solía suceder a cada gran aguacero (Olcina Cantos, 2004).

Tres acciones paralelas, complementarias entre sí, se pusieron en marcha en la inmediata posguerra, a fin de alcanzar el objetivo perseguido. Por un lado, se procedió a la declaración de utilidad pública de los trabajos proyectados en cada una de las subcuencas que vertían sus aguas a los ríos que desembocaban en los embalses de Valdeinfierno y Puentes. Por otro lado, el Estado desarrolló una política encaminada a disponer del suelo preciso para llevar a cabo las medidas programadas. En unos casos adquirió ese suelo a través de la compra directa a sus legítimos propietarios, que se lo habían ofrecido previamente de forma vo-

${ }^{12}$ Confederación Sindical Hidrográfica del Segura. Memoria relativa a la implantación del servicio forestal de aplicaciones de la confederación. $4^{a}$ parte. Archivo de la Confederación Hidrográfica del Segura. Legajo 318. 
luntaria, mientras que en otros recurrió a la expropiación para hacerse con su control. Por último, la administración forestal se valió de la figura del consorcio para poder disponer de aquellos montes que mayor interés presentaban de cara a su corrección hidrológica y repoblación forestal.

La primera declaración de utilidad pública se produjo en $1944^{13}$; afectaba a la cuenca de Rambla Seca, un afluente del río Alcaide que desembocaba directamente en el embalse de Valdeinfierno. El proyecto de corrección y restauración de esta cuenca, como llegó a ser tan frecuente en estos años (Araque Jiménez y Sánchez Martínez, 1994), se encargó a Vicente Peña, alumno de último curso de la Escuela Técnica Superior de Ingenieros de Montes de Madrid (Peña, 1940). Entre las recomendaciones que se hacían en este proyecto fin de carrera figuraba en un lugar destacado la adquisición inmediata de toda la porción forestal de la sierra de las Almohallas, cerro de Calderón y serrata de Guadalupe (1.800 has.). Respecto a las especies a emplear en la repoblación, se apostaba por el pinus halepensis, bien por plantación o mediante siembras. En cuanto a los diques de corrección hidrológica, después de un pausado estudio, se sugería la construcción generalizada de diques de 3 de metros de altura por 1 metro de espesor, ya que resultaban los más apropiados para las condiciones de la cuenca, y los más ventajosos desde el punto de vista económico.

A esta declaración le siguió, cuatro años después ${ }^{14}$, la de la cuenca de Rambla Mayor, otro de los afluentes del mismo río donde más necesaria resultaba la acción encaminada a la corrección hidrológica. En ambos casos, la decisión implicaba la posibilidad de emprender los trámites de la expropiación forzosa de los terrenos de propiedad privada delimitados dentro de cada una de las cuencas, de acuerdo con lo preceptuado en la ley de 10 de enero de 1879 y en su reglamento de 30 de junio de 1879.

A mediados de 1949, cuando todavía no se habían iniciado los trabajos de corrección y repoblación en ninguna de las dos cuencas, se promulgó la ley por la cual se establecían normas especiales para llevar a cabo los trabajos de restauración hidrológico-forestal en la cuenca del Segura ${ }^{15}$. Conocida entre el personal forestal como «Ley del Segura» (Montiel Pinilla, 1955), la norma venía a dar respuesta a los desastres ocasionados por las fuertes inundaciones que habían tenido lugar en distintos momentos de la década de los años cuarenta (Gil Olcina, 1968; Conesa García, 1985), a raíz de uno de los cuales, el de diciembre de 1944, el ingeniero jefe de la tercera división hidrológico-forestal, Juan Antonio

${ }_{13}$ Decreto de 29 de septiembre de 1944. Boletín Oficial del Estado. 19 de octubre de 1944.

${ }^{14}$ Decreto de 26 de noviembre de 1948. Boletín Oficial del Estado. 16 de diciembre de 1948.

${ }^{15}$ Ley de 16 de julio de 1949. Boletín Oficial del Estado. 18 de julio de 1949. 
Pérez Urruti, redactó un informe en el que propuso la repoblación y corrección de las distintas ramblas murcianas (Peña Urmeneta, 1946). Su entrada en vigor obligó a modificar los decretos de utilidad pública que se habían promulgado con anterioridad, para adaptarlos al nuevo marco legal. Esa decisión se tomó después de que se delimitara, por decreto aparecido a comienzos de $1950^{16}$, la primera zona de aplicación de la ley, en la que quedaron integradas todas aquellas subcuencas que vertían aguas al Segura en las que mayores peligros ofrecía la deforestación de sus laderas ${ }^{17}$. Los decretos correspondientes a la declaración de utilidad pública de las distintas subcuencas pertenecientes a la zona que estudiamos, empezaron a aparecer en el Boletín Oficial del Estado a mediados de 1950 y se extendieron hasta comienzos de 1969. En las siete subcuencas establecidas, cuya extensión total alcanzaba las 85.016 hectáreas (cuadro 1), se fijaron para repoblación 18.198 hectáreas, lo que significaba sólo un 21,4%. En cambio, el volumen conjunto de las obras proyectadas se elevaba hasta los $5.796 .636 \mathrm{~m}^{3}$, si bien es verdad que el grueso de las mismas se concentraba en la subcuenca de la Rambla Mayor, donde se concentraban el 99 \% de las mismas.

Cuadro 1. Declaraciones de utilidad pública

\begin{tabular}{|l|l|r|r|r|}
\hline $\begin{array}{c}\text { Decreto } \\
\text { declaración }\end{array}$ & \multicolumn{1}{|c|}{ Cuenca } & $\begin{array}{c}\text { Superficie } \\
\text { de cuenca } \\
\text { (Has.) }\end{array}$ & \multicolumn{1}{c|}{$\begin{array}{c}\text { Superficie } \\
\text { repoblación } \\
\text { (Has. })\end{array}$} & $\begin{array}{c}\text { Volumen } \\
\text { de obras } \\
\left(\mathbf{m}^{3}\right)\end{array}$ \\
\hline $\begin{array}{l}29-9-1944 / \\
5-6-1950\end{array}$ & Rambla Seca & 3.922 & 890 & 5.739 .572 \\
\hline $\begin{array}{l}26-11-1948 / \\
16-5-1950\end{array}$ & Rambla Mayor & 14.120 & 6.441 & 6.470 \\
\hline $11-5-1951$ & Río Alcaide & 21.332 & 4.722 & 9.979 \\
\hline $26-7-1956$ & Río Claro & 8.700 & 3.133 & 25.973 \\
\hline $17-3-1966$ & Rambla del Cantar & 4.734 & 623 & 4.812 \\
\hline $14-11-1968$ & Cuenca alta de Chirivel & 32.208 & 1.073 & 4.459 \\
\hline $16-1-1969$ & Cuenca baja de Chirivel & & 1.316 & 5.371 \\
\hline Total & & 85.016 & 18.198 & 5.796 .636 \\
\hline
\end{tabular}

Fuente: Boletín Oficial del Estado. Elaboración propia.

${ }^{16}$ Decreto de 24 de febrero de 1950. Boletín Oficial del Estado. 10 de marzo de 1950.

${ }^{17}$ Los límites quedaron configurados de la siguiente forma: al Norte, la divisoria de la cuenca del río Quipar con las del Guadalentín y Mula, y línea de los términos municipales de Bullas, Mula, Ricote, Abarán, Fortuna y Abanilla, que quedaban dentro de la zona; al Este, el límite de las provincias de Alicante y Murcia; al sur, la divisoria del Guadalentín con la que vierte aguas directamente al Mediterráneo, o a través del río Almanzora; al Oeste, la divisoria occidental de la cuenca del Guadalentín. 
Como preceptuaba la ley de 1949, en las zonas delimitadas dentro de cada subcuenca el Ministerio de Agricultura se reservaba la potestad de llevar a cabo, previa notificación a sus propietarios, los trabajos de construcción de diques de retención y obras de consolidación de terrenos que estimara pertinentes, así como de efectuar las repoblaciones artificiales y establecer los acotamientos al pastoreo que resultaran más convenientes a los fines perseguidos. Eso sí, cuando la intervención administrativa implicara la repoblación forestal, los propietarios de los montes afectados podían optar por cualquiera de estas cuatro soluciones: repoblar por su cuenta la zona señalada a cambio de una subvención estatal que podía elevarse hasta el $65 \%$ del coste de la misma; autorizar al Ministerio de Agricultura a ejecutar la repoblación, reintegrando al mismo, al menos, el $25 \%$ de su coste total; arrendar al Estado los terrenos a repoblar por un plazo comprendido entre 10 y 20 años, al cabo de los cuales el propietario debería reintegrar los gastos efectuados o ceder en propiedad el predio repoblado contra el abono estatal del precio del suelo y, finalmente, si no se aceptaba ninguno de los procedimientos anteriores, el Estado podía imponer a la propiedad privada el arrendamiento forzoso, o directamente proceder a la expropiación de la finca deseada.

No obstante, antes de que entrara en vigor esta ley, algunas de las sociedades y propietarios privados de montes ya habían procedido a la venta de la totalidad o de una parte sustancial de sus propiedades. En 1942, como se observa en el cuadro 2, el P.F.E. procedió a la adquisición del primer predio, Sierra Larga y Estepares, cuya extensión (1.748,7 has.) era producto de la agrupación de seis montes que en ese momento se hallaban en manos de la Compañía de Productos Resinosos, S. A., quien lo ofertó voluntariamente al ente estatal. Esta empresa, constituida en Madrid en 1923, llegó a convertirse en la segunda empresa del ramo más importante de España, tras la Unión Resinera Española (Uriarte Ayo, 2000). Disponía de una pequeña fábrica de destilación de resinas en la dehesa de la Alfahuara que fue adquirida por la Unión Resinera Española en 1943, cuando ya se encontraba en plena decadencia.

Cuatro años más tarde se adquirió la dehesa de la Alfahuara (levante) (1.578,1 has.), el único predio que, como ya dijimos, había quedado en poder de la casa marquesal tras la refundición de dominios, debido, sin duda, a sus excelentes aptitudes cinegéticas. En el momento de deslindarse este monte, a mediados de 1955, se propuso la permuta de una pequeña fracción del mismo por otra de idéntica cabida que se hallaba en manos privadas, la denominada dehesa de la Alfahuara (poniente) (13,7 has.), con el fin de que la totalidad del monte quedara bajo una misma linde. Esa permuta se oficializó en 1962. 
Una década después de adquirirse La Alfahuara pasó a manos del Estado el monte El Mancheño (1.225,6 has.), que como Sierra Larga se originó por la fusión de cuatro montes más pequeños pertenecientes a distintos propietarios privados que los habían adquirido en su día directamente a la casa marquesal, o que los habían comprado a Pascual Arias a medida que éste fue desprendiéndose de su patrimonio, bien de forma voluntaria, bien acuciado por las deudas.

En total, en estos tres predios el P.F.E. invirtió casi 3,5 millones de pesetas, a cambio de las cuales se hizo con un patrimonio de más de cinco mil hectáreas. Si comparamos los precios a los que se adquirieron estos montes con los que este organismo pagó, como media, en los años 1942, 1946 y 1956 en el resto de las adquisiciones efectuadas $^{18}$, podrá comprobarse el buen negocio que realizó el Estado en Sierra Larga y El Mancheño, ya que ambos se adquirieron a un precio considerablemente inferior a la media nacional. En cambio, la compra de la dehesa de la Alfahuara no resultó tan ventajosa, pues el precio que se satisfizo por metro cuadrado triplicó al promedio del país, ya que presentaba un aceptable estado de conservación.

A partir de los años sesenta, el ritmo de adquisiciones se incrementó, si bien es verdad que buena parte de las fincas adquiridas a partir de entonces fueron de una extensión diminuta. Las dos excepciones más llamativas se registraron a comienzos y al final de la década de los setenta, cuando se compraron en dos grandes lotes el conjunto de montes de Los Barrancos, con casi 5.000 has. de cabida conjunta. Como antes se ha dicho, estos montes se hallaban al Norte del término municipal de Vélez Blanco y fueron adquiridos por Pascual Arias tras la refundición de dominios. No obstante, una parte de los mismos (1.487 has.) ya los había vendido con anterioridad a 1935 a José Portillo, y otra (1.565 has.) se había sacado a venta en subasta pública ese año por deudas contraídas con el Banco Español de Crédito. Tanto éstos como el resto de los montes que ahora adquiría el P.F.E. resultaban fundamentales para la corrección hidrológica de la rambla Mayor y del río Alcaide, uno de los principales objetivos del máximo órgano forestal en aquellos momentos.

La última de las fórmulas empleadas fue el establecimiento de consorcios con cada uno de los tres ayuntamientos de la zona, así como con distintos propietarios privados. Mediante este tipo de acuerdos, los dueños cedían sus montes al P.F.E. para que éste procediera de forma inmediata a la repoblación forestal de los mismos, asumiendo el organismo estatal la totalidad de los gastos que comportaba dicha operación, así como los que acarreaba la gestión posterior de

18 Información del Patrimonio Forestal del Estado. Resumen de las adquisiciones. Años 1940-1957. Montes. No 81. 1958. Pág. 211. 
las masas creadas, incluyendo los gastos en guardería forestal. En el momento en que los montes o las partes de los mismos objeto de consorcio entraran en producción, los beneficios generados por su explotación se repartirían según los porcentajes establecidos en las bases del acuerdo, correspondiendo al Estado, que pasaba a ser dueño del vuelo creado, una parte muy superior, generalmente, a la de los propietarios cedentes, quienes, en todo caso, continuaban siendo los legítimos propietarios del suelo de los montes (Maraver Juan, 1999).

Cuadro 2. Adquisición de montes

\begin{tabular}{|l|l|r|r|r|}
\hline \multicolumn{1}{|c|}{ Municipio } & \multicolumn{1}{|c|}{ Fecha } & \multicolumn{1}{c|}{$\begin{array}{c}\text { Superficie } \\
\text { (Has.) }\end{array}$} & \multicolumn{1}{c|}{ Importe } \\
\hline Vélez Blanco & Sierra Larga y Estepares & 1942 & $1.748,7$ & 300.000 \\
\hline María & Dehesa de la Alfahuara Levante & 1946 & $1.578,1$ & 1.122 .103 \\
\hline Vélez Blanco & El Mancheño & 1956 & $1.225,6$ & 829.407 \\
\hline María & Dehesa de la Alfahuara Poniente & 1962 & 13,7 & 0 \\
\hline Vélez Blanco & Cueva Torrente & 1965 & 438,2 & 922.420 \\
\hline Vélez Blanco & Carrizalejo & 1965 & 149,0 & 290.740 \\
\hline Vélez Blanco & Los Barrancos & 1971 & $2.864,0$ & 5.844 .300 \\
\hline Vélez Blanco & Barranco de los Mellados & 1971 & 10,0 & 20.000 \\
\hline María & Almagara y Cruz del Muerto & 1972 & 215,0 & 724.280 \\
\hline María & Cortijo Real & 1973 & 32,2 & 112.100 \\
\hline María & El Entredicho & 1973 & 44,0 & 135.000 \\
\hline Vélez Blanco & El Madroño & 1978 & 10,6 & 85.000 \\
\hline Vélez Rubio & Sitio de la Dehesa & 1978 & 27,2 & 150.000 \\
\hline Vélez Blanco & El Madroño Alto I & 1978 & 13,9 & 112.000 \\
\hline Vélez Rubio & El Cortijo & 1978 & 16,4 & 140.000 \\
\hline Vélez Blanco & El Madroño Alto II & 1978 & 18,9 & 150.000 \\
\hline Vélez Blanco & Los Barrancos & 1978 & $1.916,0$ & 14.000 .000 \\
\hline Vélez Blanco & El Madroño Alto B & 1978 & 28,9 & 232.000 \\
\hline María & Cortijo Real & 1979 & 22,2 & 5.105 \\
\hline María & Los Panizos & 98,0 & 1.500 .000 \\
\hline Total & & $10.470,6$ & 26.674 .455 \\
\hline
\end{tabular}

Fuente: Archivo del Ministerio de Medio Ambiente. Elaboración propia.

De acuerdo con los datos procedentes del Archivo del Ministerio de Medio Ambiente, en los tres municipios se consorciaron un total de 30 montes que ocupaban una superficie superior a las 10.000 has. El ayuntamiento que mayor número de consorcios estableció con el P.F.E fue, lógicamente, el de Vélez Blanco, 
que entregó al ente estatal casi todos los montes que poseía mancomunadamente con Vélez Rubio desde la refundición (cuadro 3). También tuvieron una cierta importancia los consorcios efectuados con distintos propietarios privados en este municipio, pues alcanzaron las 2.640,3 has. ${ }^{19}$. Muy lejos de éste quedaron el Ayuntamiento de María, que efectuó cuatro consorcios que afectaron a 649,3 has., y el de Vélez Rubio, que sólo sometió a consorcio el monte Sierra de las Estancias con 602 has.

Cuadro 3. Consorcio de montes

\begin{tabular}{|l|r|r|r|r|}
\hline & \multicolumn{2}{|c|}{ Ayuntamientos } & \multicolumn{2}{c|}{ Particulares } \\
\hline \multicolumn{1}{|c|}{ Ayuntamiento } & $\mathbf{N}^{\text {o de montes }}$ & $\begin{array}{c}\text { Superficie } \\
\text { (Has) }\end{array}$ & $\mathbf{N}^{\text {o de montes }}$ & $\begin{array}{c}\text { Superficie } \\
\text { (Has) }\end{array}$ \\
\hline María & 4 & 649,3 & 1 & $\mathrm{Sd}$ \\
\hline Vélez Blanco & 14 & $6.607,4$ & 5 & 2.640 .3 \\
\hline Vélez Rubio & 1 & 602,0 & 5 & 55,0 \\
\hline Total & 19 & $7.858,7$ & 11 & $2.695,3$ \\
\hline
\end{tabular}

Fuente: Archivo del Ministerio de Medio Ambiente. Elaboración propia

A medida que el P.F.E. se fue haciendo con el control de la amplia base patrimonial que acabamos de cifrar, procedió de inmediato a su repoblación forestal. Durante la década de los años cuarenta, debido a la crónica carencia de medios materiales y humanos, la repoblación hubo que circunscribirla a aquellos montes que presentaban mayores problemas de deforestación, en especial a los recién adquiridos Sierra Larga y Estepares y dehesa de la Alfahuara, en los cuales se repoblaron 770 y 250 has., respectivamente, o sea, el 80 \% de toda la superficie repoblada en ese decenio (cuadro 4). El ritmo repoblador se incrementó en la década siguiente, en la que se consiguieron repoblar 1.941 has. repartidas entre 15 montes, dentro de los cuales sobresalió la ya citada Sierra de las Estancias, en la que se repobló la totalidad de la superficie consorciada. En los años sesenta, aunque la superficie repoblada creció ligeramente hasta alcanzar las 2.085 has., su concentración espacial también resultó muy elevada, pues sólo en el monte El Mancheño se repobló casi la mitad de esa superficie. La prioridad que se asignó a la repoblación de cada uno de esos montes en los diferentes momentos históricos estuvo asociada, obviamente, a su papel estratégico de cara a la contención de los arrastres en las cabeceras de las diferentes cuencas hidrográficas.

19 Esta superficie corresponde únicamente a tres consorcios. De los otros dos, la fuente manejada no ofrece la superficie que se contemplaba en la base del consorcio. 
Cuadro 4. Superficie repoblada. 1940-1970

\begin{tabular}{|c|c|c|c|c|}
\hline Municipio & Monte & $\begin{array}{c}\text { 1941-1950 } \\
\text { (Has.) }\end{array}$ & $\begin{array}{c}1951-1960 \\
\text { (Has.) }\end{array}$ & $\begin{array}{c}1961-1970 \\
\text { (Has.) }\end{array}$ \\
\hline María & Dehesa Afahuara Levante & 250 & - & - \\
\hline María & Umbría de la Virgen y otros & - & 45 & - \\
\hline María & Umbría de la Virgen (Estado) & 28 & - & - \\
\hline María & Perentín & - & 80 & 50 \\
\hline María & Lomas de Tejera & 127 & - & - \\
\hline María & Hoya Labat y Cerro Julián & - & - & 160 \\
\hline Vélez Blanco & Las Almohallas & 20 & 10 & - \\
\hline Vélez Blanco & Sierra Larga y Estepares & 770 & 100 & - \\
\hline Vélez Blanco & Serrata de Guadalupe & - & 55 & - \\
\hline Vélez Blanco & Los Andaluces & - & - & 50 \\
\hline Vélez Blanco & Las Cañicas & - & 40 & - \\
\hline Vélez Blanco & Solana de Perentín & - & 30 & 80 \\
\hline Vélez Blanco & Los Maimones y Quemados & - & 100 & 400 \\
\hline Vélez Blanco & Cerros del Almez, Carretas & - & - & 200 \\
\hline Vélez Blanco & El Mancheño y otros & - & 105 & 985 \\
\hline Vélez Blanco & Montes de Vélez Blanco & - & 220 & - \\
\hline Vélez Blanco & El Peñascal, La Hoya & 10 & - & - \\
\hline Vélez Blanco & Cerro de Calderón & 60 & - & - \\
\hline Vélez Blanco & El Pinar & - & 16 & 60 \\
\hline Vélez Blanco & Monte de Vélez Umbría & - & 100 & - \\
\hline Vélez Blanco & Monte de Vélez Solana & - & 370 & 100 \\
\hline Vélez Blanco & Los Campos y otros & - & 70 & - \\
\hline Vélez Rubio & Montes públicos de Vélez Rubio & - & 600 & - \\
\hline Total & & 1.265 & 1.941 & 2.085 \\
\hline
\end{tabular}

Fuente: P.F.E. Inventario de repoblaciones en 31-12-1970. Elaboración propia.

Los sistemas de repoblación forestal fueron cambiando con el paso de los años, tal y como han expuesto Alcocer Martínez y otros (1998). Hasta el inicio de la década de los sesenta, tanto las labores de preparación del terreno como las de plantación se llevaban a cabo de forma manual, lo que confirió a la obra repobladora un fuerte calado social, en la medida en que permitió absorber una buena parte de la mano de obra desempleada en unas comarcas rurales fuertemente empobrecidas. A partir de los años sesenta gran parte de esas labores se mecanizaron, lo que redujo la impronta social de la política de repoblación, al tiempo que 
se incrementaron los impactos ambientales como consecuencia de la carencia de maquinaria específica apropiada para la preparación de las terrazas subsoladas.

En cuanto a las especies empleadas en la repoblación, como puede apreciarse en el cuadro 5 y MAPA 3, el dominio absoluto correspondió al pino carrasco (pinus halepensis), que se empleó en 4.911 de las 5.291 has. repobladas, esto es, en casi el 93 \% de la superficie afectada. Tanto el pino rodeno (pinus pinaster) como el pino laricio (pinus nigra) se emplearon de forma meramente testimonial. En el primer caso, en el monte Los Maimones y Quemados, y en el segundo, en el monte Perentín. Esta consagración monoespecífica al pino carrasco estaba en perfecta consonancia, como ya hemos visto, con lo que habían previsto los redactores de los proyectos, si bien en algún caso, como en el de la repoblación de las cuencas de las Ramblas de Nogalte y Viznaga, se había sugerido también la plantación de 400.000 pies de frondosas, sin especificar, y 200.000 de tarayes (tamarix gallica), así como la plantación de más de 80 has. de chumberas (Peña Urmeneta, 1946).

Del mismo modo que había venido sucediendo desde sus inicios, la actuación reforestadora se completó con la construcción de numerosas obras de corrección hidrológica tanto en las vertientes como en los propios cauces de los arroyos y ramblas. La mayor disponibilidad de créditos consagrados a estas labores permitió la ejecución de un gran número de diques de corrección transversales a los cauces, cuya finalidad fundamental consistía en la retención de sedimentos, para evitar que éstos aterraran los embalses situados en la cabecera del Guadalentín, así como disminuir la velocidad del agua y su capacidad erosiva (Romero Díaz, 2008).

\section{CONCLUSIONES}

A pesar de que desde el último cuarto del siglo XIX la política de corrección hidrológico-forestal había asignado la máxima prioridad a la intervención en la cabecera de la cuenca del Guadalentín, el confuso estado jurídico en que se encontraban sus montes obligó a retrasar esta acción hasta bien entrado el siglo XX. Durante el primer tercio de esa centuria los trabajos avanzaron a un ritmo muy lento, debido, en primer lugar, a las escasas consignaciones presupuestarias que se destinaron al logro de ese objetivo, máxime si tenemos en cuenta las elevadas inversiones que requerían los trabajos de corrección y, sobre todo, la adquisición de los montes susceptibles de intervención. Por otro lado, no hay que olvidar que durante todos estos años la mayor parte de las inversiones de la División Hidrológico-Forestal del Segura se concentraron en Sierra Espuña, presentada ante el cuerpo técnico y la opinión pública como el mejor ejemplo de los favorables efectos que traía aparejada la política de repoblación forestal aplicada a la montaña mediterránea. 
Cuadro 5. Especies utilizadas en la repoblación forestal. 1940-1970

\begin{tabular}{|c|c|c|c|c|}
\hline Municipio & Monte & $\begin{array}{c}\text { Pinus } \\
\text { halepensis } \\
\text { (Has.) }\end{array}$ & $\begin{array}{c}\text { Pinus } \\
\text { pinaster } \\
\text { (Has.) }\end{array}$ & $\begin{array}{c}\text { Pinus } \\
\text { nigra } \\
\text { (Has.) }\end{array}$ \\
\hline María & Dehesa Afahuara Levante & 250 & - & - \\
\hline María & Umbría de la Virgen (Consorciado) & 45 & - & - \\
\hline María & Umbría de la Virgen (Estado) & 28 & - & - \\
\hline María & Perentín & - & - & 130 \\
\hline María & Lomas de Tejera & 127 & - & - \\
\hline María & Hoya Labat y Cerro Julián & 160 & - & - \\
\hline Vélez Blanco & Las Almohallas & 30 & - & - \\
\hline Vélez Blanco & Sierra Larga y Estepares & 870 & - & - \\
\hline Vélez Blanco & Serrata de Guadalupe & 55 & - & - \\
\hline Vélez Blanco & Los Andaluces & 50 & - & - \\
\hline Vélez Blanco & Las Cañicas & 40 & - & - \\
\hline Vélez Blanco & Solana de Perentín & 110 & - & - \\
\hline Vélez Blanco & Los Maimones y Quemados & 250 & 250 & - \\
\hline Vélez Blanco & Cerros del Almez, Carretas & 200 & - & - \\
\hline Vélez Blanco & El Mancheño y otros & 1.090 & - & - \\
\hline Vélez Blanco & Montes de Vélez Blanco & 220 & - & - \\
\hline Vélez Blanco & El Peñascal, La Hoya & 10 & - & - \\
\hline Vélez Blanco & Cerro de Calderón & 60 & - & - \\
\hline Vélez Blanco & El Pinar & 76 & - & - \\
\hline Vélez Blanco & Monte de Vélez Umbría & 100 & - & - \\
\hline Vélez Blanco & Monte de Vélez Solana & 470 & - & - \\
\hline Vélez Blanco & Los Campos y otros & 70 & - & - \\
\hline Vélez Rubio & Montes públicos de Vélez Rubio & 600 & - & - \\
\hline Total & & 4.911 & 250 & 130 \\
\hline
\end{tabular}

Fuente: P.F.E. Inventario de repoblaciones en 31-12-1970. Elaboración propia

Tras la Guerra Civil española el panorama cambió drásticamente al incrementarse sustancialmente las dotaciones presupuestarias, pero también como consecuencia de la promulgación de una legislación mucho más intervencionista que aspiraba, por encima de todo, a poner bajo control estatal una masa de montes cada vez más amplia, con el fin de aplicar en ellos las propuestas correctoras y repobladoras que sólo parcialmente habían podido desarrollarse durante la etapa anterior. Mediante la adquisición de fincas o a través del es- 


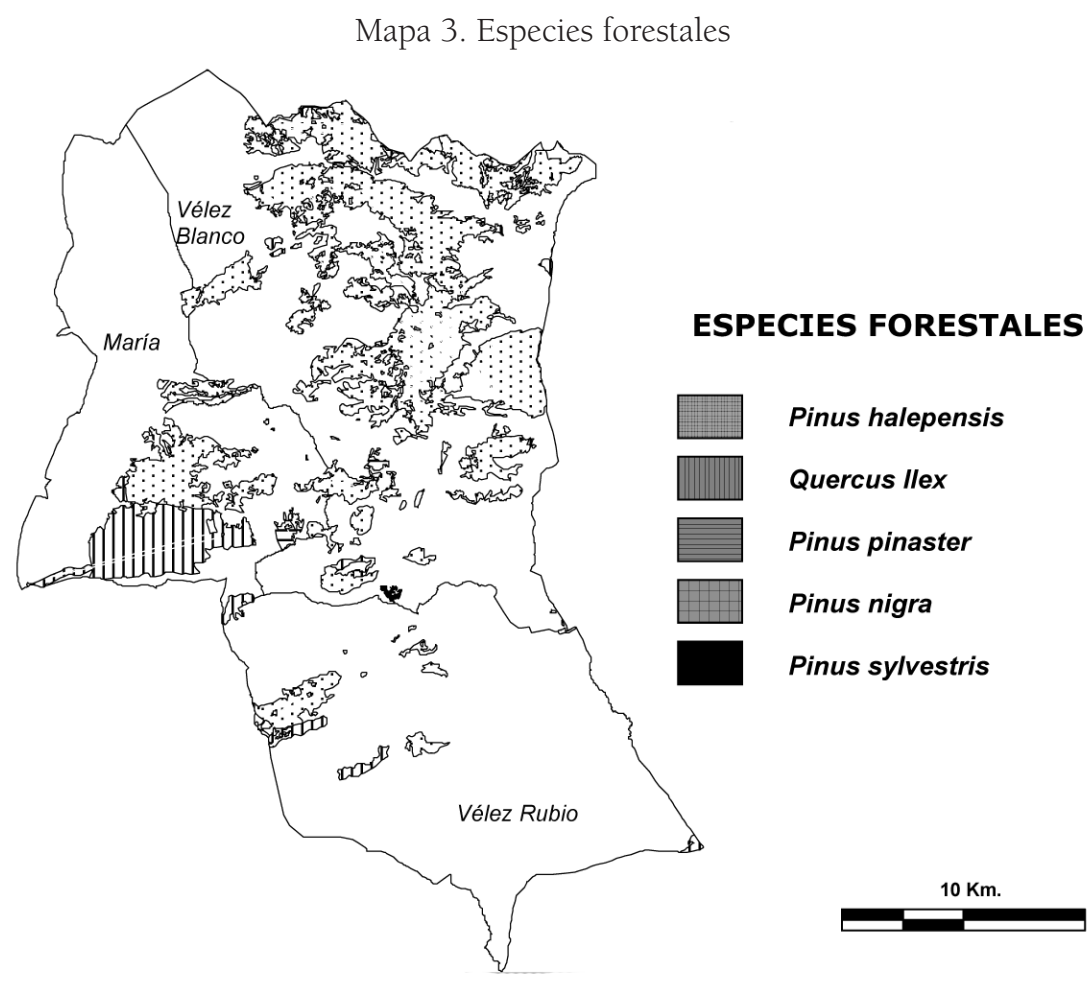

Fuente: II Inventario Forestal Nacional. Elaboración propia.

tablecimiento de consorcios, el P.F.E. logró hacerse con una base patrimonial nada despreciable, a la que aplicó todas sus energías materiales y humanas en pos de recuperar la cubierta arbórea que tan eficaz resultaba a la hora de mitigar los efectos erosivos de las copiosas precipitaciones en la cabecera del Guadalentín.

Las actuaciones llevadas a cabo hasta 1970, con ser muy importantes, no bastaron para erradicar las desastrosas inundaciones en la cuenca, como trágicamente se puso de manifiesto en 1973 en la rambla de Nogalte, cuyo desbordamiento arrasó Puerto Lumbreras provocando casi un centenar de muertos e infinidad de destrozos materiales. De ahí que desde entonces hasta el día de la fecha, sin interrupción, se hayan redoblado los esfuerzos para evitar la reiteración de esta clase de desastres.

De lo que no queda duda, en todo caso, es del relevante papel que se ha asignado a la porción andaluza de la cuenca del Guadalentín por parte del gobierno andaluz, que declaró una gran parte de la misma Parque Natural en 1989, estableciendo sobre la misma un régimen de protección específico 
encaminado a salvaguardar sus especiales atributos naturales. La adopción de semejante figura de protección se debió, en gran medida, a la labor realizada por el P.F.E. tanto en la vertiente patrimonial como reforestadora, pues sin la masa actual de montes públicos, cubiertos en su mayor parte por el manto pinariego que comenzó a fraguarse en los años cuarenta, la declaración del Parque Natural de la Sierra de María-Los Vélez no hubiera sido posible.

\section{BIBLIOGRAFÍA}

Alcocer Martínez, F. y otros (1998): «La gestión de los montes de María y Vélez Blanco en el último siglo», en Encuentro medioambiental almeriense: en busca de soluciones. http://www.gem.es/materiales/document/documen/g07/ d07207/d07207.htm

Andujar Castillo, F. (1996): «Los montes de los Vélez en el siglo XVI», en Sánchez Picón, A. (Ed.): Historia y medio ambiente en el territorio almeriense. Almería. Servicio de Publicaciones de la Universidad de Almería. Págs. 83-97.

Anónimo (1893): «La comisión de repoblación de la cuenca del Segura». La Reforma Forestal. No 22. Págs. 4-6.

Anónimo (1907): «Tercera división hidrológico-forestal. Estado de los trabajos al terminar el año 1906». Revista de Montes. No 739. Págs. 641-646.

Araque Jiménez, E. y Sánchez Martínez, J. D. (1994): «Ingenieros de Montes en las Sierras de Segura y Cazorla durante los años cuarenta». Boletín del Instituto de Estudios Giennenses. No 153. Tomo II. Págs. 617-632.

Azcona Elayo, J. (2004): «Memoria sobre la refundición de dominio de los montes de María y Vélez Blanco por incompatibilidad de servidumbre. Selección, transcripción y comentarios». Revista Velezana. № 23. Págs. 197-206.

Barrios Aguilera, M. (2007): «El marquesado de los Vélez en el siglo XVI. Estado de la cuestión y líneas de investigación», en Andújar Castillo, F. y Pablo Díaz López, J. P.: Los señoríos en la Andalucía Moderna. El Marquesado de los Vélez. Almería. Instituto de Estudios Almerienses. Págs. 15-36

Calvo García-Tornel, F. (1968-1969): «La huerta de Murcia y las avenidas del Guadalentín». Papeles del Departamento de Geografía. No 1. Págs. 111-137.

Carretero Zamora, J. M. (2007): «Régimen señorial y fiscalidad regia en época de Carlos V: el marquesado de los Vélez», en Andújar Castillo, F. y Pablo Díaz López, J. P.: Los señoríos en la Andalucía Moderna. El Marquesado de los Vélez. Almería. Instituto de Estudios Almerienses. Págs. 37-56.

Codorniú, R. (1897-1898): «La Sierra de Espuña y su repoblación forestal». Revista de Montes. No 498. Págs. 533-538. Pág. 499. Págs. 561-566. № 500. Págs. 606-611. No 501. Págs. 633-637. No 502. Págs. 661-663. № 504. Págs. 
29-33. No 505. Págs. 49-51. No 506. Págs. 77-79. No 509. Págs. 157-160. No 511. Págs. 213-218. No 512. Págs. 233-236. No 513. Págs. 261-265. No 514. Págs. 297-300. No 517. Págs. 378-380.

Codorniú, R. (1906): «Lluvias en septiembre de 1906 en la división hidrológicoforestal del Segura». Revista de Montes. No 717. Págs. 661-669. № 718. Págs. 693-701.

Conesa García, C. (1985): «Inundaciones en Lorca (Murcia): riesgo y expectación». Papeles de Geografía Física. No 10. Págs. 33-47.

CORTÁzAR, M. (1875): «Reseña física y geológica de la región norte de la provincia de Almería». Boletín de la Comisión del Mapa Geológico de España. Tomo II. Págs. 161-234.

Espejo Marín, C. y Calvo García-Tornel, F. (2003): «Bibliografía sobre riesgos con origen en procesos naturales publicada en España (1975-2002)». Biblio 3W. Revista bibliográfica de Geografía y Ciencias Sociales. Vol. VIII. No 455. 25 de julio de 2003. http://www.ub.es/geocrit/b3w-455.htm

Felices de la Fuente, M. M. y Giménez Carrillo, D. M. (2007): «Rentas y propiedades a mediados del siglo XVIII: el Marqués de los Vélez y su señorío almeriense», en Andújar Castillo, F. y Pablo Díaz López, J. P.: Los señoríos en la Andalucía Moderna. El Marquesado de los Vélez. Almería. Instituto de Estudios Almerienses. Págs. 351-377.

Franco Silva, A. (1995): El marquesado de los Vélez (siglos XIV-mediados del XVI). Murcia. Consejería de Cultura y Educación.

García, R. y Gaztelu, L. (reed. 2001): Proyecto de obras de defensa contra las inundaciones del Valle del Segura. Murcia. Confederación Hidrográfica del Segura.

Gil Olcina, A. (1968): «El régimen del río Guadalentín». Cuadernos de Geografía. No 5. Págs. 1-19.

Gil Olcina, A. (2001): «Un hito en el estudio y defensa de las inundaciones en la cuenca del Segura: el proyecto de 1886», en García, R. y Gaztelu, L.: Proyecto de obras de defensa contra las inundaciones del Valle del Segura. Murcia. Confederacón Hidrográfica del Segura. Págs. 35-58.

Gil Olcina, A. (2004): «Hiperembalses dieciochescos de Puentes y Valdeinfierno», en Gil Olcina, A. (Dir.): La cultura del agua en la cuenca del Segura. Murcia. Fundación Cajamurcia. Págs. 277-309.

Gil Olcina, A. y Morales Gil, A. (Edic.) (1989): Avenidas fluviales e inundaciones en la cuenca del Mediterráneo. Alicante. Instituto Universitario de Geografía de la Universidad de Alicante y Caja de Ahorros del Mediterráneo.

Gómez MendozA, J. (1989): «La discusión técnica en torno a la política hidráulica y a la política forestal antes del Plan Nacional de Obras Hidráulicas», en Los 
paisajes del agua. Libro jubilar dedicado al profesor Antonio López Gómez. Universidades de Valencia y Alicante. Págs. 85-96.

Gómez Mendoza, J. y Mata Olmo, R. (1992): «Acciones forestales públicas desde 1940: objetivos, criterios y resultados». Agricultura y Sociedad. № 65. Págs. 15-64.

Gómez Mendoza, J. y Mata Olmo, R. (2002): «Repoblación forestal y territorio (1940-1971): marco doctrinal y estudio de la Sierra de los Filabres (Almería)». Ería. No 58. Págs. 129-155.

Lentisco Puche, J. D. (1993): «Los montes velezanos a finales del siglo XIX». Revista Velezana. No 12. Págs. 113-120.

Lentisco Puche, D. (1996): «De despensa agrícola a recurso turístico. Evolución y transformación del monte velezano (Siglos XVI-XX)», en Sánchez Picón, A. (Ed.): Historia y medio ambiente en el territorio almeriense. Almería. Servicio de Publicaciones de la Universidad de Almería. Págs. 203-220.

Maraver JuAn, E. (1999): «Los consorcios y la administración: una historia que no debe ser interminable. Aplicación particular a los montes de Sierra Morena». Montes. $N^{\circ}$ 57. Págs. 61-66.

Martínez Artero, J. A. (2001): «Repoblaciones hidrológico-forestales en la cuenca del río Guadalentín». Montes. No 65. Págs. 66-69.

Mira, F. (1917): «Trabajos realizados en la división hidrológico-forestal del Segura». Revista de Montes. No 959. Págs. 3-11.

Montiel Pinilla, F. (1955): «La lucha contra la erosión en la cuenca del río Segura». Montes. No 65. Págs. 349-354.

Motos Miras, S. (1960): Estudio ecológico-forestal de los Montes del Partido Judicial de Vélez-Rubio (Almería). Proyecto fin de carrera. Escuela Técnica Superior de Ingenieros de Montes. Universidad Politécnica de Madrid.

Olcina Cantos, J. (2004): «Precipitaciones escasas, irregulares e intensas: sequías e inundaciones», en Gil Olcina, A. (Dir.): La cultura del agua en la cuenca del Segura. Murcia. Fundación Cajamurcia. Págs. 91-134.

Peña, V. (1940): Proyecto de corrección y restauración forestal de Rambla Seca. Proyecto fin de carrera. Escuela Técnica Superior de Ingenieros de Montes. Universidad Politécnica de Madrid.

Peña Urmeneta, A. (1946): Proyecto de corrección y repoblación forestal de las cuencas de las Ramblas de Nogalte y Viznaga (Provincias de Almería y Murcia). Proyecto fin de carrera. Escuela Técnica Superior de Ingenieros de Montes. Universidad Politécnica de Madrid.

ReYes, E. DE LOS (1900): «Pantanos y repoblaciones». Revista de Montes. № 573. Págs. 624-629. 
Romero Díaz, A. (2008): «Los diques de corrección hidrológica como instrumentos de cuantificación de la erosión». Cuadernos de Investigación Geográfica. N ${ }^{\circ}$ 34. Págs. 83-99.

Roth, D. (2008): Vélez Blanco en el siglo XVI. Desde la época morisca a la sociedad de la repoblación. Almería. Instituto de Estudios Almerienses.

SÁnchez Picón, A. (1992): La integración de la economía almeriense en el mercado mundial (1778-1936). Cambios económicos y negocios de exportación. Almería. Instituto de Estudios Almerienses.

Serrano de la Pedrosa, F. (1886): Las inundaciones y la repoblación forestal. Madrid. Tipografía de Dionisio de los Ríos.

Tapia, J. A. (1964): Vélez Blanco. La villa señorial de los Fajardo. Madrid. Hauser y Menet.

Uriarte Ayo, R. (2000): La Unión Resinera Española (1936-1986). Madrid. Fundación Empresa Pública. ftp://ftp.funep.es/phe/hdt2005.pdf. 